\title{
Nationes y consensus universorum en la propaganda visual augustea
}

\author{
Fabiola SALCEDo GARCÉS \\ Universidad Complutense de Madrid \\ fsalcedo@ghis.ucm.es
}

\section{RESUMEN}

A través de varios casos conocidos de cultura visual, se aborda la doble propaganda romana de conquista basada en la doble estrategia contrapuesta de consenso y dominio. Esta propaganda, existente ya en tiempos de la República, experimentará una nueva dimensión en época de Augusto, quien promoverá - a través de diversos canales de propaganda - el mensaje de consenso.

Palabras clave: Augusto. Nationes. Propaganda. Consenso. Iconografía.

\section{Nationes and Consensus Universorum in the Visual Propaganda of Augustus}

\begin{abstract}
By looking at various known cases of visual culture, this paper addresses the dual Roman conquest propaganda based on the two-pronged strategy of consensus and coercion. This propaganda, already existing back in the times of the Republic, came into its own in the times of Augustus, who drove the message of consensus through diverse propaganda channels.
\end{abstract}

Key Words: Augustus. Nationes. Propaganda. Consensus. Iconography. 
El estudio de la iconografía romana de nationes o provincias, a pesar de la historiografía existente, no deja de aportar nuevas miradas y reflexiones. ${ }^{1}$ Como punto de partida, señalaremos la idea fundamental, ya apuntada en diversas ocasiones, de que en el imaginario romano, no sólo se representan provinciae en sentido administrativo, sino también ethne, nationes, populi, gentes; en definitiva, muy diversos pueblos integrados en el ámbito del poder romano o, al menos, pertenecientes a la esfera de su influencia.

Es también importante resaltar que en los mensajes difundidos a través de dichas imágenes se hizo patente una doble propaganda aparentemente contrapuesta: la alusiva al consenso y la paz, y la que instaba al sometimiento a Roma, mostrando al pueblo en cuestión en un aspecto ajeno a la romanitas.

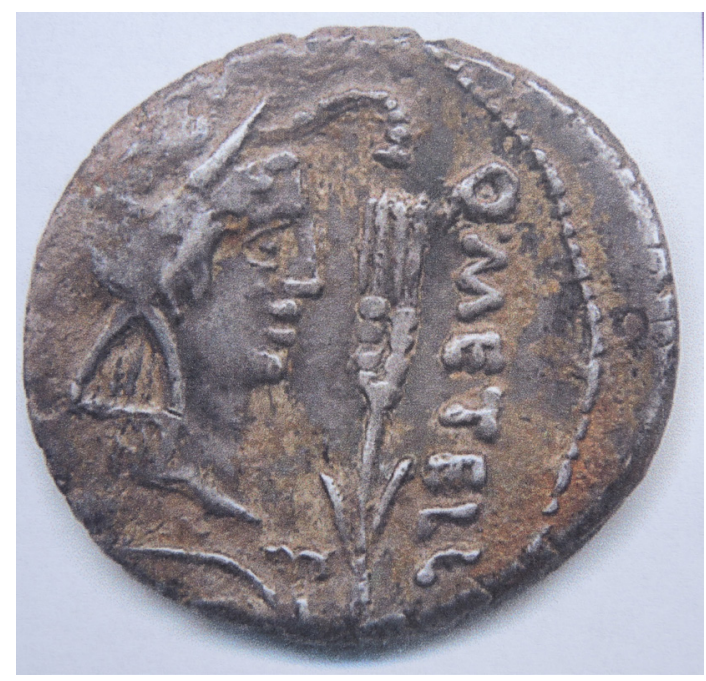

Fig. 1. Ar. Denarius. Q. Metell.Scipio. 47-46 a.C. Cabeza de Africa con las exuviae elephantis. (RRC 461-1).

La fórmula visual más eficaz de consenso se lograba mediante emblemas que contenían alguna referencia al imaginario propio de una cierta natio, transmitiendo así una idea de "respeto". Es ésta una estrategia de dominio - usual ya desde tiempos de la República - basada en la interpretatio romana de un icono prerromano, que tras su asimilación y alteración semántica, es de nuevo difundido como símbolo de cohesión social en una comunidad étnicamente heterogénea. Es un recurso que A. Wachtel definió como "desposesión del mundo indígena", al analizar procesos similares en la conquista de América. ${ }^{2}$

Los iconos elegidos pueden ser animales, armas, divinidades prerromanas y sus sacra, o cualquier otro símbolo de poder asentado en la memoria visual colectiva. Así

1 Amplia bibliografía sobre el tema en SALCEdo 1996; también SAPELLi 1999.

2 WaChTEL 1992. 
sucedió para la provincia Africa, con la utilización de las exuviae elephantis -evocación de la efigie de Alejandro Magno, ya asentada entre los reinos númidas - ${ }^{3}$ (Fig. 1) o la imagen de Sekhmet (Genius Terrae Africae), de clara raigambre púnica (Fig. 2), o bien del triskeles, para Sicilia. ${ }^{4}$ (Fig. 3).

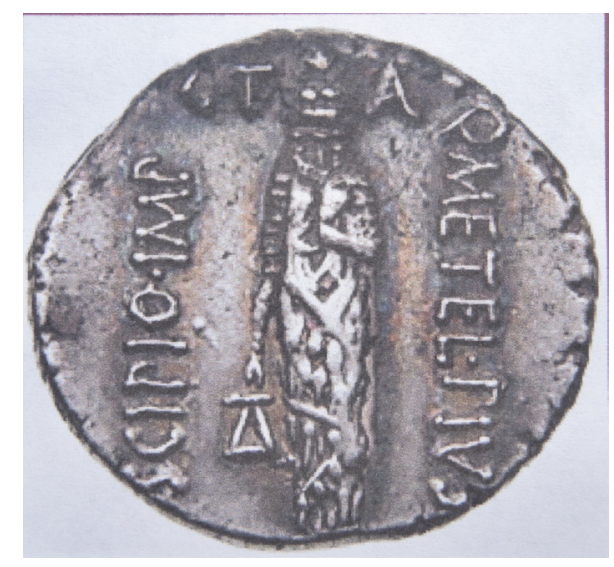

Fig. 2. Ar. Denarius. P. Licinius Crassus -Q. Caecilus Metellus Pius Scipio. 47-46 a.C. Genius Terrae Africae. (RRC 460-4).

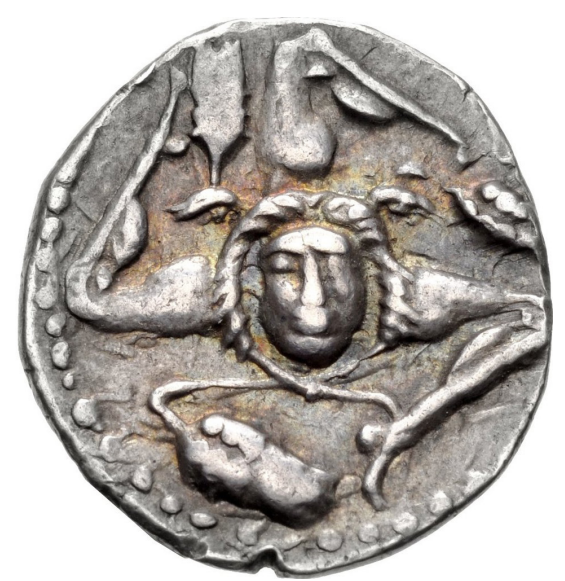

Fig. 3. Ar.Denarius. L. Lentulus.C.Marc Cos. 49 a.C. Triskeles. (RRC 445-1a,1b).

Este modelo conceptual "respetuoso" de la imagen indígena evolucionará o se vinculará al modelo de personificaciones femeninas denominadas pia fidelis, máxima expresión de la integración de las nationes en la Oikoumene romana.

3 La primera imagen alusiva a la provincia de África es la de Hiarbas de Numidia, del 108 a.C., que copia la efigie de Alejandro Magno, SALCEDo 1996, 73, 123 ss.

4 Sobre la adopción del triskeles como emblema provincial romano de Sicilia, SALCEDo 1994. 
Por el contrario, el mensaje de sometimiento se transmitía presentando a un cierto ethnos o pueblo como ajeno a la civilización, a la romanidad, con los rasgos estereotipados de la barbarie en sus diferentes versiones, casi siempre presentando a los enemigos como cautivos atados a trofeos o exaltando, a veces, la clementia imperial. ${ }^{5}$ Ambas formas de representación convivirán a lo largo del tiempo y perdurarán hasta el final del Imperio.

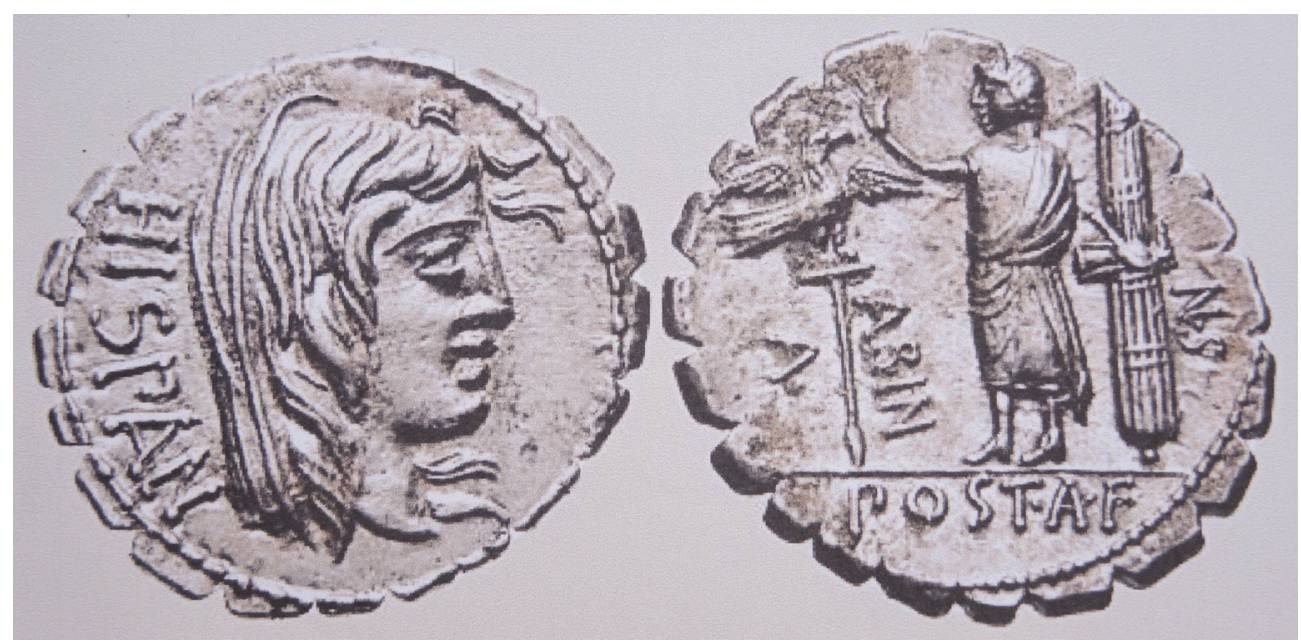

Fig. 4. AR Denarius, A. Postumius Albinus, 81 a.C. Hispania. (RRC 372/2).

En época de Augusto, que es la que observaremos aquí, esta doble estrategia de dominio se hace patente en numerosos testimonios de carácter público, desde las monedas - el soporte iconográfico más eficaz, por su alcance y difusión - hasta monumentos y esculturas, tanto en Roma, como en las provincias. En casi todos los casos, siempre está presente la alusión al princeps. Lo que promueve Augusto en numerosos casos es intervenir en una tradición anterior, dándole una dimensión hasta ahora desconocida en la que la idea de poder se conjuga con la del consenso.

En el caso de Hispania, o mejor, las Hispaniae, hay que comenzar señalando que la primera imagen alusiva a la provincia es la que aparece en el año 81 a.C., como una personificación femenina que responde al estereotipo visual de bárbaro (Fig. 4). ${ }^{6}$ No es Hispania la única en representarse como tal. También Galia, en las acuñaciones de Hostilius Saserna del 43 a.C. (Fig. 5), se representa siguiendo el mismo estereotipo en el anverso, pero conjugándose, en el reverso, con el icono sagrado del territorio: la Diana de Éfeso, diosa tutelar de Marsella.

5 SAlcedo 1996, 33 ss. Magistral artículo a este respecto el de MARCo 2012.

6 Tema abordado en SALCEDO 1995. 


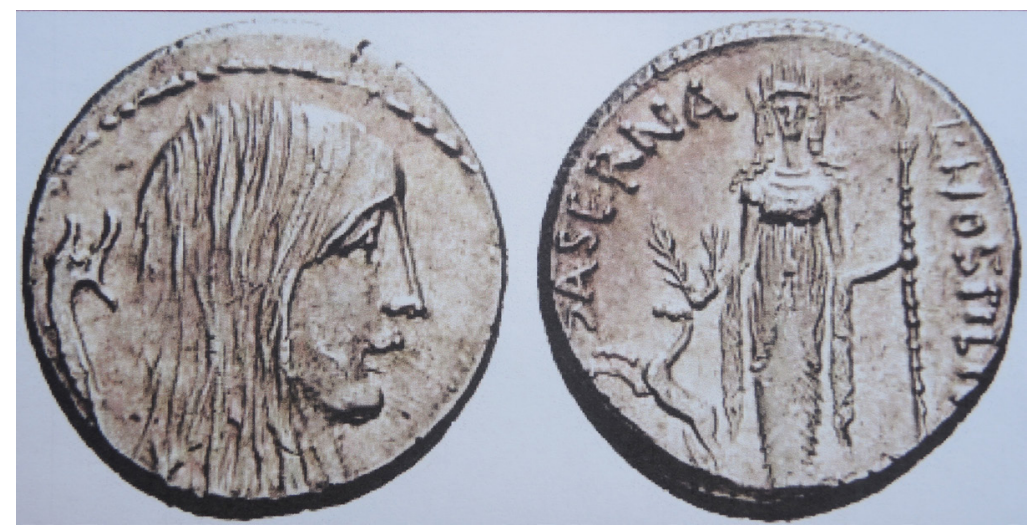

Fig. 5. AR Denarius, L. Hostilius Saserna, 43 a.C. Gallia. (RRC 448-3).

Pero casi sesenta años después de esta Hispania barbara, entra en escena, en tiempos de Augusto, un emblema que suscita la idea de consenso a la que aludíamos. En los denarios acuñados por Publio Carisio en Mérida en el año 23 a.C., ${ }^{7}$ aparece la cabeza de Augusto en el anverso, mientras que el reverso presenta una serie de armas vinculadas al imaginario del territorio lusitano (Strabo, III 3.6): escudo pequeño o caetra, puñal o cuchillo y una falcata que, si bien, como sabemos, es propia del mundo ibérico, los romanos la asociaban de manera genérica a los hispanos. (Fig. 6).

Dichas armas - rodela y falcata - como propuso tan perspicazmente $\mathrm{M}^{\mathrm{a}} \mathrm{Paz}$ Garcia y Bellido,${ }^{8}$ corresponden a los sacra de una divinidad prerromana -la lusitana Ataecina - asimilada a Tanit, que se veneraría en el suroeste peninsular, en la zona de la Beturia túrdula, territorio con diversos oppida habitados por poblaciones indígenas de celtas y túrdulos. ${ }^{9}$

Con la llegada de los bárquidas a Iberia, en el contexto de la segunda guerra púnica, llegaron también numerosos libios semitizados ${ }^{10}$ que - procedentes quizá del territorio gaditano - acabarían asentándose en dichos oppida, cohabitando con los indígenas túrdulos y dando paso a diversos procesos de sincretismos y asimilaciones, como el de Tanit con Ataecina.

Ya avanzada la segunda mitad del s. II a.C., tras la derrota de Cartago, estas comunidades de origen libio-fenicio acuñaron moneda con metrología romana y leyendas bilingües: en neopúnico y latín. Son las llamadas emisiones libiofenicias, ${ }^{11}$ acuñadas en Turrirecina ${ }^{12}$ (Fig. 7) o Turri Regina - identificada con Casas de Reina, Badajoz ${ }^{13}$.

7 Anv./ Imp Caesar Avgvs; Rev./ Carisivs Leg Pro Pre. Cfr. García-Bellido 2010, 162, fig. 3.c.

8 García-Bellido 2010, 162-163.

9 RodríGuez DíAz - Ortiz Romero 2003, 219 y ss.

10 Se trata de caballeros mauri y númidas (líbico-bereberes) que llegaron a Iberia con Aníbal, con vistas a su campaña itálica (Polibio, III 33.15). Sobre las posibles cleruquías cartaginesas, cfr. GARCíA-BELLIDO 2013, 303 ss.

11 Escritas con rasgos caligráficos líbicos: "verticales y angulosos", Dominguez Monedero 1995, 112. QuESADA 1992: 113-114; 1997: 487.

12 García-Bellido 2010, 162, fig. 3.a.

13 García-Bellido 2010. 


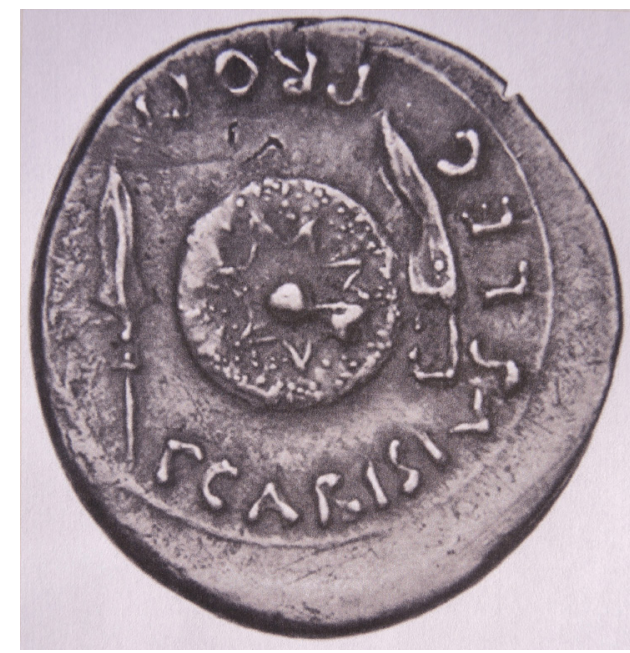

Fig. 6. AR Denarius. Emerita, 25-23 a.C. P CARISIVS LEG PRO PR. Rev.: rodela y falcata. $R I C \mathrm{I}^{2}, 1984,2$ a.

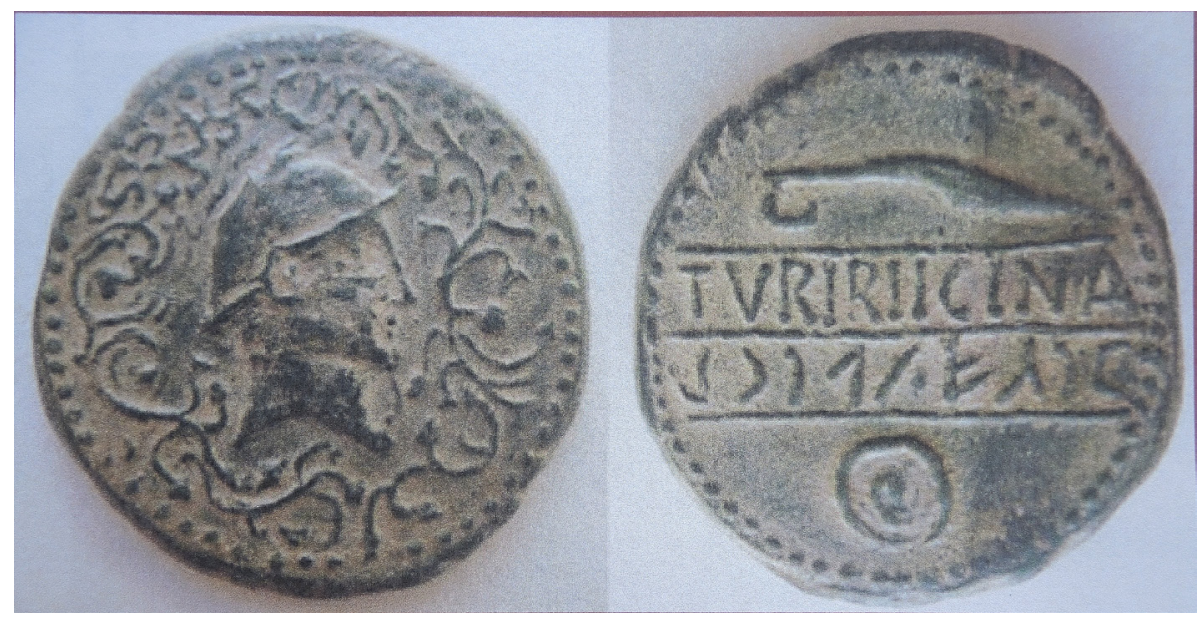

Fig. 7. Bronce. Turrirecina. $2^{\mathrm{a}}$ mitad s. II a.C. Anverso: efigie galeada de Ataecina; rev.: armas (sacra) de Ataecina.

Este caso no es algo singular; situaciones similares las encontramos en otros emplazamientos ibéricos, como Obulco, Carisa,${ }^{14} \mathrm{u}$ otros del Mediterráneo, como el de Aradus (Fenicia), en cuyas acuñaciones aparece la imagen de Augusto asociada a Astarté. ${ }^{15}$

14 Por ejemplo, celtíberos, íberos y vetones con el icono del jinete ibérico, cfr. Arévalo 2003; GarcíABellido 2010,157; para las de Obulco, cfr. ArÉvalo 2002-2003, 250.

15 BMC 356. 
Pero, como advertíamos, esta apariencia de respeto convive con el mensaje de sometimiento. Valga como ejemplo señalar que es en esta época (19 a.C.) cuando se crea un icono monetal de pueblo vencido - partos o armenios - implorando amicitia. ${ }^{16}$

En el caso de Hispania, la misma serie de P. Carisio cuenta con monedas en las que se representan trofeos, en clara alusión a la guerra y al sometimiento de los cántabros. ${ }^{17}$ También de época augustea es el Tropaeum Alpium o trofeo de La Turbie, erigido poco después del sometimiento de las tribus alpinas por Augusto en el 14 a.C. ${ }^{18}$ El monumento triunfal, de unos 50 metros de altura, coronado por la estatua broncínea de Augusto, sigue una interesante tipología arquitectónica bastante común en la Galia Narbonense. Enmarcada por relieves con trofeos, se desplegaba una enorme inscripción ( 17 x 3,66 m) sobre la fachada principal (W) del basamento cuadrangular, en la que, tras la dedicatoria a Augusto, aparecen los tituli de 45 tribus ligures y gentes alpinae devictae (CIL V, 7817):

\begin{abstract}
IMP $\cdot$ CAESARI DIVI FILIO AVG $\cdot$ PONT $\cdot M A X \cdot I M P \cdot X I I I \cdot T R \cdot P O T \cdot X V I I \cdot S$ $\cdot P \cdot Q \cdot R \cdot Q V O D$ EIVS DVCTV AVSPICIISQVE GENTES ALPINAE OMNES QVAE A MARI SVPERO AD INFERVM PERTINEBANT SVB IMPERIVM P $\cdot R \cdot S V N T R E-$ DACTAE - GENTES ALPINAE DEVICTAE TRVMPILINI · CAMVNNI - VENOSTES - VENNONETES - ISARCI · BREVNI - GENAVNES - FOCVNATES - VINDELICORVM GENTES QVATTVOR · COSVANETES · RVCINATES · LICATES · CATENATES · AMBISONTES $\cdot$ RVGVSCI $\cdot$ SVANETES $\cdot$ CALVCONES $\cdot$ BRIXENETES $\cdot$ LEPONTI $\cdot$ VBERI - NANTVATES · SEDVNI - VARAGRI - SALASSI - ACITAVONES - MEDVLLI · CENNI $\cdot$ CATVRIGES $\cdot$ BRIGIANI $\cdot$ SOGIONTI $\cdot$ BRODIONTI $\cdot$ NEMALONI $\cdot$ EDENATES - VESVBIANI - VEAMINI - GALLITAE - TRIVLLATI - ECDINI - VERGVNNI ·

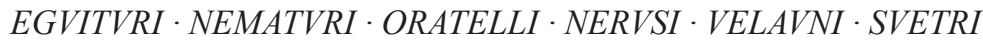

Probablemente, entre las estatuas que se exhibirían en los intercolumnios del cuerpo circular, podrían contemplarse las personificaciones de algunas de las nationes sometidas.

\title{
Consensus universorum de Augusto
}

Volviendo a la estrategia de consenso, también Augusto redimensionó una tradición heredada de épocas anteriores. Una práctica utilizada desde época helenística fue la de los desfiles de personajes representativos de ciudades y pueblos conquistados en los ceremoniales de estado. La procesión más famosa, descrita por Ateneo, fue la de Ptolomeo II (s. III a.C.) en la que desfilaron personajes femeninos que representaban, con plena dignidad, a las ciudades liberadas del dominio persa, tales como Corinto.

Roma heredaría esta costumbre como forma de propaganda. El testimonio más antiguo, en este sentido, se remonta al año 188 a.C. Tito Livio (37.59) nos cuenta que

16 Armenios: Denario 19/4 a.C., Roma, P. Petronius Turpilianus, RIC 291. BMCRR 21. Partos: Denario 19/18 a.C. Roma, P. Petronius Turpilianus. RIC 289.

17 García-Bellido, BlázQuez 2001: s.v. 4.

18 Formigé 1949; Lamboglia 1955; Crema 1959, N. 25; Binninger 2006. 
en el desfile triunfal de Lucio Escipión Asiageno desfilaron oppidorum simulacra. El modelo iconográfico de estas imágenes de ethne o nationes sería el de las alegorías griegas de ciudades o territorios, que no fueron otra cosa que personificaciones femeninas. Así aparece, por ejemplo, Etolia, Hellas o la famosa Tyche de Antioquía, de Eutíquides de Sición.

Esta tradición de desfiles triunfales es de la misma naturaleza y tiene el mismo valor simbólico que la idea de presentar listas o series de nationes y ethne conquistadas, acompañadas o no de personificaciones u otros elementos alusivos. El mensaje de poder de esta estrategia reside precisamente en el carácter impactante del elenco de pueblos referenciados. Piénsese, por ejemplo, en las alusiones que hace el propio Augusto en las Res gestae (25-31) a los pueblos conquistados o en su propio funeral, en el que desfilaron los simulacra de nationes, tal y como nos transmiten Tácito ( $A n$ nales 1.8.4) y Dión Cassio (56.34.2-3).

\section{Ara de Lyon}

Uno de los monumentos donde se pone en práctica la estrategia de asimilación/alteración de tradiciones prerromanas es el altar de Lyon, tan sólo conocido por las fuentes literarias ${ }^{19}$ y por la iconografía monetal (Fig. 8). ${ }^{20}$

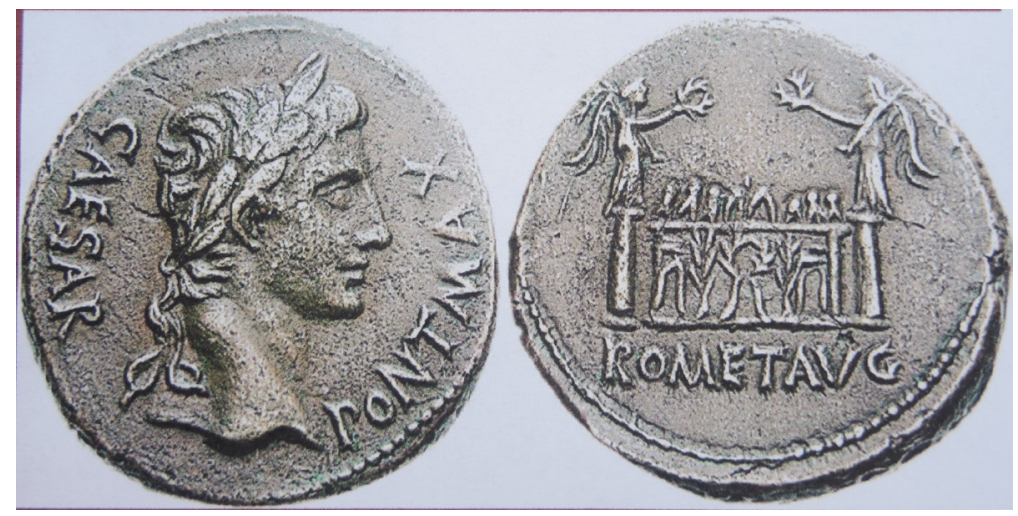

Fig. 8. Æ As. Lugdunum 15/10-10/7 a.C RIC 230; Lyon 7.

El lugar elegido para levantar el altar no era otro que el santuario federal de las tres Galliae, lugar sagrado para los galos, donde tenían lugar rituales y festivales anuales dedicados a Lug, rey mítico celta revestido de rasgos divinos. ${ }^{21}$ Allí, en la confluencia del Ródano con el Saona, ${ }^{22}$ en la falda de la colina de Croix-Rousse, convocó Druso

\footnotetext{
19 Strabo (4.3.2); Tácito (Ann. 3.44) ; Serv,. Aen. I 286; Ptol., Geog. 2.7-9.

$20 Æ$ As. Lugdunum 15/10-10/7 a.C. RIC 230; Lyon 73. BMCRE I, 92-93, nº 548-560, figs. 20, 20; 94-96, $\mathrm{n}^{\mathrm{o}}$ 565-588, figs. 21, 1-2, 4-5; 127, no 62-64, figs. 26,10; 196, no 227, fig. 37,10; 395, no 587 bis.

21 CIL XII, 227-230; TurCAN 1982; Bellen 1984, 385-396.

22 Liv., Perioch. 139; Cass. Dio, 54.32; Suet., Claud. 2.
} 
el 1 de agosto del año 12 a.C. a los jefes tribales para una ceremonia en la que Augusto sería coronado como dios celta Lugus y fue erigido un altar dedicado a Roma y Augusto, cuya consagración debió de tener lugar dos años más tarde, el 1 de agosto del 10 a.C., coincidiendo con el nacimiento de Claudio en Lugdunum. ${ }^{23}$ Como alarde de consenso entre Roma y las poblaciones sometidas, junto a las estatuas representativas de los pueblos celtas, se inscribieron en el altar los tituli de sus nationes: 60, según Estrabón (4.3.2); 64, según Tácito (Ann. 3.44): At Romae non Treviros modo et Aeduos sed quattuor et sexaginta Galliarum civitates descivisse, adsumptos in societatem Germano (...).

Se sellaba así un pacto de fidelidad entre las poblaciones galas con su nuevo caudillo - Augusto - perpetuando la costumbre celta ancestral de juramento de fidelidad eterna - en la vida y en la muerte - al jefe tribal, investido de un aura sobrehumana, algo que encontramos entre otros pueblos, como los íberos. Recuérdese el episodio del tribuno de la plebe M. Ampudio quien exortó a la multitud a rendir fidelidad a Octavio el día en que el Senado le nombró Augustus, el 16 de enero del año 27 a.C., aludiendo a que "se le consagraba según la costumbre de los íberos". Sin duda, Augusto aprovechó esta tradición de la devotio indígena para garantizarse la fidelidad a su persona y a Roma.

\section{Ara Pacis Augustae}

Otro espacio donde se representaron series de nationes, entre las que se encontraría Hispania, fue en el Friso del pódium del altar del Ara Pacis, algo que se trató de recomponer años después de la inauguración del monumento en 1938.

Tras la ardua tarea de ensamblaje de las piezas, aún quedaron varios cientos de fragmentos esparcidos en los almacenes del Museo Nazionale Romano, que han sido objeto de varias hipótesis de reconstrucción. ${ }^{24}$

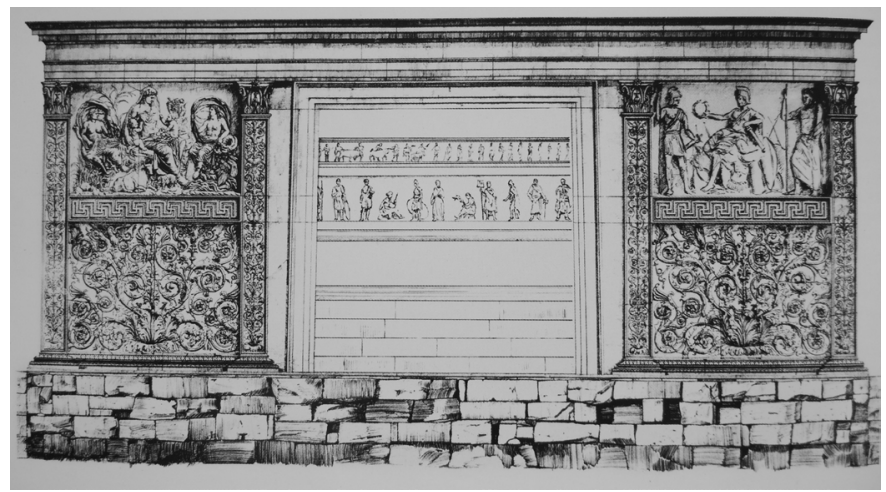

Fig. 9. Reconstrucción sg. Moretti y Gatti, 1948. Un único friso con figuras de nationes.

23 CIL XII, 227-230; TurCan 1982, 607-644; Bellen 1984; TurCan 1991.

24 De Angelis Bertolotti 1985, 221-234; Koeprel 1987, 146-151; Settis 1988, 426, n..230. 
A la hipótesis de G. Moretti y G. Gatti, de 1948, que proponía un único orden para las figuras (Fig. 9), siguió la de Kähler ${ }^{25}$ en 1954, quien abogaba por la existencia de 66 distribuidas alrededor del altar en dos órdenes: uno, grande, con figuras de $88 \mathrm{~cm}$ de altura y otro con figuras de $65 \mathrm{~cm}$ de alto. (Fig. 10).

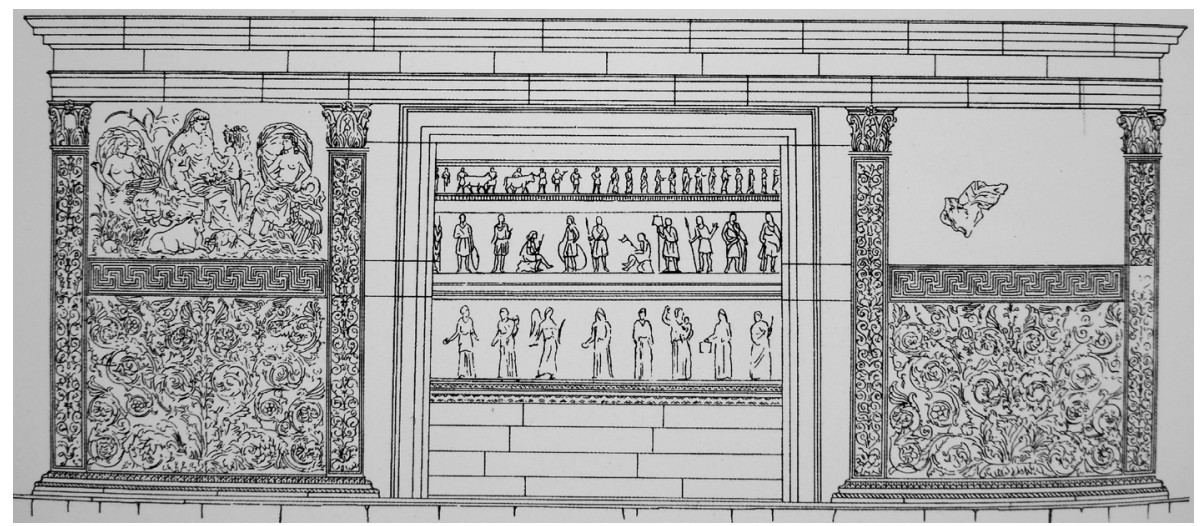

Fig. 10. Reconstrucción sg. Kähler 1954. Dos frisos con figuras de nationes.

\section{Forum Augusti}

Un caso muy representativo de la propaganda augustea sería la exhibición de los Tituli gentium en su Foro de Roma. Uno de los temas discutidos es la presencia de estatuas representativas, como pudo ser la imagen de Hispaniae, a raíz de un conocido pasaje de Velleyo Patérculo (2.39.2): Divus Augustus praeter Hispanias aliasque gentis, quarum titulis forum eius praenitet, paene idem facta Aegypto stipendiaria, quantum pater eius Galliis, in aerarium reditus contulit.

G. Alföldy ${ }^{26}$ puso en relación este texto con la inscripción de una base estatuaria alusiva a la Bética: Imp(eratori) Caesari / Augusto p(atri) p(atriae) / Hispania ulterior / Baetica quod / beneficio eius et / perpetua cura / provincia pacata / est auri / p(ondo) C. (CIL VI, 3127). Según la nueva propuesta formulada por Alföldy y apoyada por otros estudiosos, ${ }^{27}$ la estatua - situada en el "Aula del Coloso" - no sería una de Augusto - tal y como se ha interpretado hasta ahora - dedicada por la provincia Bética, sino la propia personificación de la Bética.

25 Kähler 1954, 97.

26 AlFÖLDY 1989, 226-234.

27 LiVERANi 1995, 221. 


\section{Porticus ad nationes}

Uno de los casos más interesantes y en el que comprobamos cómo Augusto interviene y redimensiona un espacio republicano es el caso de la controvertida Porticus ad nationes, en la que se representaban los simulacra omnium gentium, es decir, todas las estatuas de nationes o gentes, entre las que se encontraría, con toda probabilidad, Hispania o alguna de su provincias. Basándose en la tradición de Servio (Serv., Aen. VIII 721), el pórtico en cuestión se habría levantado en época de Augusto, sin embargo, la lectura de otras fuentes ha hecho pensar en otra posible interpretación.

Junto al teatro de Pompeyo, ${ }^{28}$ en el llamado Hecatostylum (Pórtico de las cien columnas) o Porticus Lentulorum, se erigían, según testimonio de Plinio (N.H. XXXVI 41), Suetonio (Nero 46) y del propio Servio (ad Aen. VII 721), las estatuas -hoy perdidas en su mayoría- de catorce personificaciones de nationes conquistadas por Pompeyo, realizadas por el escultor Coponio. No tenemos constancia de los nombres de dichas nationes, pero un pasaje de Diodoro Sículo (40.4) señala que sus nombres estaban inscritos en un epígrafe colocado en el propio templo de la Venus Victrix del teatro. ${ }^{29}$ La visión final del problema apunta a que las nationes de Coponio debieron de ser subsumidas dentro del programa llevado a cabo por Augusto, quien, cuando reformó el teatro de Pompeyo, las colocó en su nueva Porticus ad nationes. ${ }^{30}$

\section{BibLIOGRAFÍA}

AlföLDY, G. (1989): “Zu den Monumenten der römischen Provinzen auf dem Augustus-forum", [en] Drexhage, H. J. - Sünskes, J. (eds.), Migratio et Commutatio. Studien zur Alten Geschichte und deren Nachleben. Thomas Pekáry zum 60. Geburtstag, St. Katharinen, 226-234.

ArÉVAlO, A. (2002-2003): "Las imágenes monetales Hispánicas como emblemas de Estado", CuPAUAM 28-29, 241-258.

(2003): "La moneda hispánica del jinete ibérico. Estado de la cuestión”, [en] Quesada, F. Zamora, M. (eds.), El caballo en la antigua Iberia. Estudios sobre los équidos en la Edad del Hierro, Madrid, 63-74.

BINNINGER, S. (2006): “Le «Tropaeum Alpium» et l'Héraclès Monoikos : mémoire et célébration de la victoire dans la propagande augustéenne à la Turbie", [en] Navarro Caballero, M. - Roddaz, J.-M., (eds.), La Transmission de l'idéologie impériale dans les provinces de l'Occident romain : Actes du 128 ème colloque CTHS, Bastia, 15-16 avril 2003, Bordeaux, 179-203.

28 Monterroso 2010, con bibliografía anterior.

29 No tenemos constancia de los nombres de dichas nationes y tampoco se han conservado la estatuas. Hay un pasaje transmitido por Diodoro Sículo (40.4) muy revelador en este sentido, que señala que Pompeyo mandó colocar una inscripción en el propio templo de la Venus Victrix de su teatro, donde se especificaban los nombres de unas catorce nationes, muchas de ellas también presentes en la procesión triunfal que Pompeyo celebró en Roma tras sus triunfos en Oriente, tal y como cuenta Plinio el Viejo.

30 Monterroso 2008. 
BMCRE = MAtTingly, H., (1923): Coins of the Roman Empire in the British Museum, 6 vols., London.

BMCRR = GRUEBER, H A. (reed. 1970): Coins of the Roman Republic in the British Museum, 2 vols., London.

Bellen, H. (1984): “Das Drususdenkmal apud Mogontiacum und die Galliarum Civitates”, JbRGZM 31, 385-96.

Crema, L. (1959): “Architettura romana”, [en] Enciclopedia Classica, III, XII, Torino.

De Angelis Bertolotti, R. (1985): “Materiali dell'Ara Pacis presso il Museo nazionale romano", RM 92, $221 \mathrm{ss}$.

Dominguez Monedero, A. (1995): “De nuevo sobre los "libiofenicios": un problema histórico y numismático", [en] García-Bellido, Mª P. - Sobral Centeno, R. M. (eds.), La moneda hispánica. Ciudad y territorio, Anejos de Archivo Español de Arqueología 14, 111-116.

Formigé, J. (1949): Le Trophée des Alpes (La Turbie), Paris.

García-Bellido, $\mathrm{M}^{\mathrm{a}} \mathrm{P}$.

(1993b): "Las cecas libiofenicias", [en] Numismática hispano-púnica. VII Jornadas de arqueología fenicio-púnica, Ibiza, 97-146.

(2010): “Etnias y armas en Hispania: los escudos", Gladius 30, 155-170.

(2013): “CClerujías cartaginesas en Hispania? El caso de Lascuta”, [en] Acta Palaeohispanica XI, Palaeohispanica 13, 301-322.

García-Bellido, MaPP. - BlázQuez. C. (2001): Diccionario de cecas y pueblos hispánicos. I. Introducción. II. Catálogo de pueblos y cecas, Madrid.

Gros, P. (1995): “Venus Victrix, Aedes", [en] Steinby, E. M. (ed.), Lexicon Topographicum Urbis Romae V, Roma, 120-121.

KäHLER, H. (1954): “Die Ara Pacis und die augusteische Friedensideee”, Jdl 69, 67-100.

Koeppel, G. M. (1987): “Die historischen Reliefs der römischen Kaiserzeit, 5: Ara Pacis Augustae", BJb 187, 101 y ss.

Lamboglia, N. (1955): Le trophée d'Auguste à la Turbie, Bordighera.

LiVERANi, P. (1995): “'Nationes' e ‘civitates' nella propaganda imperiale”, RM 102, 219-249.

Marco, F. (2012): "Iconografía de la derrota: formas de representación del bárbaro occidental en época tardorrepublicana y altoimperial”, [en] Marco Simón F. - Pina Polo, F. - Remesal Rodríguez, J. (eds.), Vae Victis! Perdedores en el Mundo Antiguo, Barcelona.

Monterroso, A.

(2008): "Las catorce Nationes de Coponio, quae sunt circa Pompeium", [en] La Rocca, E. - León, P. - Parisi, C. (eds.), Le due patrie acquisite. Studi di Archeologia dedicati a W. Trillmich. Serie Bulletino della Commissione Archeologica Comunale di Roma. Supl.18, Roma, 277-285.

(2010): Theatrum Pompei. Forma y Arquitectura de la génesis del modelo teatral de Roma, Madrid.

QUESADA, F.

(1997): El armamento ibérico. Estudio tipológico de las armas en la cultura ibérica. Monographies Instrumentum 3. Montagnac.

(1992): Arma y símbolo: la falcata ibérica. Alicante.

RIC I ${ }^{2}=$ Sutherland, C. H. V., R. A. G. CARson (eds.) (1984): Roman Imperial Coinage, vols. 1-2, (Rev.Ed.), London. 
RRC = CRAWford M. H. (1974): Roman Republican Coinage, Cambridge.

Rodríguez DíAz, A. - Ortiz Romero, P. (2013): "Defensa y territorio en la Beturia: castros, oppida y recintos ciclópeos", [en] Morillo, A. - Cadiou, F. - Hourcade, D. (eds.), Defensa y territorio en Hispania de los Escipiones a Augusto (espacios urbanos y rurales, municipales y provinciales), Madrid.

SALCEDO, F.

(1994): “Trinakría: entre abstracción y figuración”, Ostraka, Rivista di Antichità, 3/2, 1-15. (1995): "La Hispania bárbara y la Hispania civilizada: la imagen de un concepto", Studia Historica. Historia Antigua 13-14, 181-194.

(1996): África. Iconografía de una provincia romana. Memorias de la Escuela Española de Historia y Arqueología de Roma, vol. 21, Madrid-Roma.

Sapelli, M. (ed.) (1999): Provinciae Fideles. Il fregio del tempio di Adriano in Campo Marzio, Roma.

Settis, S. (1988): "Die Ara Pacis", [en] Kaiser Augustus und die verlorene Republik, Mainz am Rhein, 400-426.

TurCan, R. (1982): “L'Autel de Rome et d'Auguste 'Ad Confluentem ”, ANRW II.12.1, 607644.

TurCan, R. (1991): “Un bimillénaire méconnu: l'assemblée des trois Gaules”, Comptes rendus des séances de l'Académie des Inscriptions et Belles-Lettres 135/4, 733-742.

Wachtel, W. (1992): La vision des vaincus. Les Indiens du Pérou devant la Conquête espagnole, 1530-1570, Paris. 